\title{
Una experiencia exitosa de competitividad de los pequeños productores en una localidad del centro-norte de México
}

\author{
Humberto de Luna-López ${ }^{\star}$, Marisol Cruz-Cruz ${ }^{* *}$, Eloy Saucedo-Estrada ${ }^{* *}$
}

* Doctor en Ciencias Sociales y Humanidades. Profesor investigador, Unidad Académica de Economía,

Universidad Autónoma de Zacatecas, México.

Correo electrónico:

humberto_deluna@yahoo.com.mx

** Doctora en Ciencias Sociales y

Humanidades. Profesor investigador,

Unidad Académica de Economía,

Universidad Autónoma de Zacatecas,

México.

Correo electrónico:

marisol_cruz_cruz@yahoo.com.mx

*** Licenciado en Economía. Presidente,

Empresa Semillas Casa Grande Zaragoza

sc de RL de Cv, México.

Correo electrónico:

shopi55@hotmail.com

Recibido: 6 de septiembre del 2015

Aceptado: 9 de noviembre del 2015

Cómo citar este artículo: De Luna-López, H., Cruz-Cruz, M. y Saucedo-Estrada, E. (2016). Una experiencia exitosa de competitividad de los pequeños productores en una localidad del centro-norte de México. Cooperativismo y Desarrollo, 24(108), 143-156. doi: http:// dx.doi.org/10.16925/co.v24i108.1264

\section{Resumen}

Propósito: exponer la competitividad de los pequeños productores o campesinos de una localidad en el centro-norte de México, gracias a la cual han transitado de un estatus de productor de autoconsumo a productor competitivo en el mercado nacional. Descripción: primero, se exponen los aspectos teóricos metodológicos de las ventajas competitivas, que es corroborado en la realidad de los pequeños productores mediante el método hipotético-deductivo. En segundo lugar, se da cuenta de las iniciativas de los pequeños productores en América Latina, quedando claro que no es una iniciativa propia de México, sino que se comparte con otros lugares. En tercer lugar, se hace una descripción situacional de los pequeños productores del Ejido Zaragoza, la pertinencia de dedicarse al cultivo de semillas de calabaza respecto a los granos básicos y, en cuarto lugar, la manera de organizarse. Punto de vista: la dependencia del pequeño productor respecto al gobierno explica en parte su incapacidad para convertirse en un agente económico competitivo. Conclusiones: sobresale la imposición de un problema empírico que se convierte en un tema académico, pero cuyo eje central es resolver un problema real, sentido por los campesinos de la zona norte de México.

Palabras clave: competitividad, dependencia, México, pequeño productor, ventaja competitiva. 


\title{
A Competitiveness Success Story of Small Producers in a Locality in North-Central Mexico
}

\begin{abstract}
Purpose: To explain the competitiveness of small producers or peasants in a locality in north-central Mexico, thanks to which they have moved from subsistence producers to competitive producers in the domestic market. Description: First, theoretical and methodological aspects of competitive advantages are discussed, which is confirmed by the reality of small producers through the hypothetical-deductive method. Secondly, the initiatives of small producers in Latin America are accounted for, making it clear that is not an initiative of Mexico alone, but it is shared with other places. Third, a situational description of small producers of Ejido Zaragoza and the relevance of engaging in the cultivation of pumpkin seeds with respect to the basic grains is provided. Fourthly, forms of organization are described. Point of view: The dependence of small producers on the Government partly explains their inability to become a competitive economic agent. Conclusions: The imposition of an empirical issue that becomes an academic subject, but whose central focus is to solve a real problem felt by the peasants of northern Mexico, is highlighted.
\end{abstract}

Keywords: competitiveness, dependence, Mexico, small producer, competitive advantage.

\section{Uma experiência bem-sucedida de competitividade dos pequenos produtores numa região do centro-norte do México}

\section{Resumo}

Propósito: expor a competitividade dos pequenos produtores ou camponeses de uma região no centro-norte do México, graças à qual eles têm transitado de um status de produtor de autoconsumo a produtor competitivo no mercado nacional. Descrição: primeiramente, apresentam-se os aspectos teórico-metodológicos das vantagens competitivas, que é corroborado na realidade dos pequenos produtores mediante o método hipotético-dedutivo. Em segundo lugar, dá-se conta das iniciativas dos pequenos produtores na América Latina, ficando evidente que não é uma iniciativa própria do México, mas sim que está presente em outros lugares. Em terceiro lugar, faz-se uma descrição situacional dos pequenos produtores do Ejido Zaragoza, a pertinência de se dedicar ao cultivo de sementes de abóbora em comparação aos grãos básicos e, por último, a forma de organização. Ponto de vista: a dependência do pequeno produtor a respeito do governo explica em parte sua incapacidade para se converter num agente econômico competitivo. Conclusões: destaca-se a imposição de um problema empírico que se torna um tema acadêmico, mas cujo eixo central é resolver um problema real, sentido pelos camponeses da região norte do México.

Palavras-chave: competitividade, dependência, México, pequeno produtor, vantagem competitiva. 


\section{Introducción}

Este artículo surge de la necesidad de dar cuenta de algunas de las formas de operar de los pequeños productores mexicanos. También conocidos como campesinos, son resultado del reparto agrario tras la conclusión de la Revolución mexicana de 1920, es decir, se han formado de la mano del Estado, que no solo los dotó de tierras, sino de financiamiento para relacionarse con la economía, logrando tener un papel destacado como proveedores de materias primas para la industria naciente, sin perder su lugar político pero claramente identificados con la tierra (Rubio, 2002, pp. 64-68).

La dependencia del pequeño productor respecto al gobierno explica en parte su incapacidad para convertirse en un agente económico competitivo. Desde su origen quedó condenado al fracaso, porque desde ahí fue formado y financiado por el Estado; es decir, no tiene un origen propio y por esto, quedó acostumbrado a recibir todo el respaldo de las instancias gubernamentales para mantenerse. Así, la retirada del Estado en la década de los noventas del siglo pasado, facilitó la pérdida de la rentabilidad de la pequeña producción.

Precisamente, la crisis de la agricultura dominada por la pequeña producción (alrededor de tres de los cinco millones de productores agrícolas) es atribuida a la excesiva intervención del Estado.

Tras la conclusión del reparto agrario ocurrido en la década de los noventa del siglo pasado, el pequeño productor comenzó a entrar en un proceso de decadencia porque al no disponer del respaldo institucional para mantener su producción, también comenzó a presentar dificultades para la comercialización, dada su falta de operatividad individual.

No obstante, no todos los pequeños productores han quedado inmersos en esa vorágine. Si bien es complejo cuantificarlos, este artículo muestra una experiencia exitosa para lograr la competitividad en un entorno adverso, cuidando y manteniendo el autoconsumo, pero con aprendizaje de gestión colectiva desde el mismo productor.

El objetivo es exponer la competitividad de los pequeños productores o campesinos de una localidad en el centro norte de México, con el cual han transitado de un estatus de productor de autoconsumo a productor competitivo en el mercado nacional.

Para ello, primero se exponen los aspectos teóricos metodológicos de las ventajas competitivas, que, mediante el método hipotético-deductivo, es corroborado en la realidad de los pequeños productores. En segundo lugar, se da cuenta de las iniciativas de los pequeños productores en América Latina, quedando claro que no es una iniciativa propia de México, sino que se comparte con otros lugares. En tercer lugar, se hace una descripción situacional de los pequeños productores del Ejido Zaragoza, mostrando la pertinencia de dedicarse al cultivo de semillas de calabaza respecto a los granos básicos. En cuarto lugar, se destacan algunos elementos de importancia sobre la manera de organizarse. Se cierra con un apartado de conclusiones, en las cuales sobresale la imposición de un problema empírico que se convierte en un tema académico, pero cuyo eje central es resolver un problema real sentido por los campesinos de la zona norte de México.

\section{La ventaja competitiva, una propuesta para comprender el éxito en los pequeños productores}

Esta investigación se aborda desde la teoría del subdesarrollo. En ella, se sostiene que una sociedad es subdesarrollada porque carece de una organización adecuada de la generación del conocimiento, destinado a mejorar los procesos productivos en los diversos sectores de la economía. No obstante, esto no impide que el capital se valorice y se continúe con el proceso de acumulación.

El capital, como en el resto de las sociedades desarrolladas, se valoriza:

Se expande y genera un plus, el cual supone cierto movimiento, esto es, el capital adquiere mercancías que por su naturaleza pueden funcionar como factores de producción: medios de producción y fuerza de trabajo. Una vez que se dispone de estos recursos, los pone a funcionar y obtiene ciertos resultados o masa de productos que destina a la venta, por los que obtiene una cierta cantidad de dinero que inicialmente gastó, siendo la diferencia entre el dinero final y el inicial lo que se reconoce como ganancia o plusvalía. Este proceso que se repite una y otra vez, es lo que se llama ciclo del capital. La fórmula de Marx es d-m-d', dinero que se transforma en mercancía y luego se recupera ese dinero incrementándolo y ese proceso se repite en sucesivos ciclos $\left(d^{\prime}-d\right)=p v$ ganancia y $\left(d^{\prime}-\right.$ d) $/ \mathrm{d}=\mathrm{g}=$ tasa de ganancia. La tasa de ganancia mide el grado de valorización del capital, el grado en que se satisface los fines del capital (Valenzuela, 2003, p. 47, citado en Cruz, 2011, p. 42). 
En la economía real, el ciclo económico es inestable en la acumulación:

A veces se expande y en otras se contrae. Estas oscilaciones muestran cierta regularidad, razón por la cual se habla de ciclo económico, es decir, un comportamiento que se asemeja a la montaña rusa; la inversión se eleva y con ello el nivel de la actividad económica luego sobreviene un periodo de descenso de inversión y del ingreso nacional (Valenzuela, 2003, p. 47, citado en Cruz, 2011, pp. 48-49).

En este tipo de economías subdesarrolladas, coexisten sociedades que tienen un funcionamiento interno contrario a la "economía normal", distinto al modelo de oferta y demanda, en el que no operan las relaciones obrero-patronales, el acceso a tecnología de punta es limitado, no tienen como objetivo la ganancia y se trabaja en las condiciones establecidas por el "dejar hacer, dejar pasar".

Una de esas sociedades es el campesinado, que, de acuerdo con la teoría del campesinado de Bartra (2006), es caracterizado por ejercer control sobre un predio que depende del temporal, produce para el autoconsumo, recurre al trabajo familiar para las diversas labores, acude a la solidaridad de otros pequeños productores para actividades donde la mano de obra de la familia es insuficiente.

La teoría del subdesarrollo es usada para comprender los rasgos de la economía en que se desenvuelve y se relacionan los pequeños productores, que se adaptan a los procesos productivos conservando algunos rasgos de su esencia campesina.

El campesinado, pese a tener una lógica de funcionamiento distinto al de la economía normal, no es ajena a ella; se relaciona con ella mediante la producción, la comercialización, el trabajo y el consumo.

En ese sentido, aparece aquí la utilidad de algunos elementos de la competitividad que suelen ser empleados para analizar el comportamiento económico de los países, conformados por empresas que determinan la competitividad.

Los aspectos teóricos de la competitividad tienen su origen en los mercantilistas, que lo asociaron a la acumulación de los metales preciosos; también lo abordó Adam Smith en La naturaleza y causas de la riqueza de las naciones, asociándolo al comercio, como un juego positivo en el cual todos los países salían beneficiados, particularmente si tenían determinadas ventajas naturales, como el trabajo,

Esta propuesta se conoce como la división internacional del trabajo o teoría de la ventaja absoluta. Fue perfeccionada por David Ricardo al orientarla al comercio internacional y exponiendo el beneficio de los países en bienes en los cuales son más eficientes de producir y comercializar. No obstante, se debe considerar que existen naciones que poseen superioridad y otros son inferiores en la producción de diversos bienes. En esos casos, el o los países se deben especializar donde tengan más ventaja o en su caso donde se tenga la menor desventaja. De esta manera, se evita el aislamiento económico, porque cada país o región se especializa en la producción de los bienes o servicios en los que el costo es menor (Buendía, 2013).

Dados los avances de las naciones, a la teoría de las ventajas competitivas se ha sumado el análisis de los factores de la producción, surgiendo de esta manera el modelo de dotación de los factores o modelo de las proporciones factoriales, concentrándose en la tierra, trabajo y el capital para predecir si un país tiene ventaja comparativa y podrá exportar aquel bien cuya producción es intensiva en el factor que está mejor dotado.

Obviamente, el factor trabajo es relativo, porque la mano de obra barata se dispone en abundancia en cualquier país y por lo tanto su costo es menor (Buendía, 2013).

La teoría clásica, sostiene Buendía (2013), ha sido opacada por los avances económicos, marcados por la globalización y el desarrollo tecnológico. Por lo tanto, la competitividad ahora está determinada por las condiciones de los factores de la producción (mano de obra especializada, infraestructura, abundancia de materias primas, entre otras), además de la deman$\mathrm{da}$, los sectores afines y las estrategias, la estructura y la rivalidad de las empresas, entre otras variables.

Las empresas operan bajo rivalidad para conseguir determinados premios, combinando:

La dirección de la empresa e innovaciones a los productos en el proceso productivo o en la organización interna, los tipos de coordinación en las fases de la cadena productiva, organización de la industria en cuanto a competencia y cooperación, y elementos de una política industrial activa que coadyuva al uso creativo y formativo del mercado. (Best, 1990, pp. 1112, citado en Sobrino, 2002, p. 312).

Como se observa, la teoría de las ventajas competitivas ha sido empleada para explicar la superioridad e inferioridad de los países; pero consideramos que proporciona elementos para comprender las decisiones de los pequeños productores para orientarse 
a los cultivos más rentables, donde tienen la menor desventaja productiva y comercial, lo cual no es sencillo de lograr porque se enfrentan a otros productores que también buscan la mejor dotación de los factores para ser competitivos.

\section{La competitividad de los pequeños productores en América Latina y México}

Los cambios de los pequeños productores para mejorar la producción, la comercialización, el nivel de ingresos y ampliar la oferta de productos primarios de origen rural no son aspectos nuevos ni exclusivos de un solo productor de México. En América Latina, encontramos un sinnúmero de cambios de los pequeños productores en los patrones de cultivo tradicional por cultivos más rentables, e incluso aprovechando los recursos de la naturaleza, particularmente los productos forestales no maderables.

Es en esta parte de América donde las iniciativas de los pequeños productores han sido incluidas en la formulación de planes de negocio para acceder a incentivos, elevando la calidad del producto al introducir maquinaria para mejorar la producción. Esto ha beneficiado a productos como el café, el banano, la leche y sus derivados, el cacao, la palma aceitera y la palta (Ministerio de Agricultura del Perú, s. f., p. 2).

Estas iniciativas de mejorar la producción y comercialización en la pequeña producción no son exclusivas de los hombres. Se encontró que, en Colombia, las mujeres que viven en contextos de pequeña producción familiar agrícola de caña y café en condiciones de pobreza, violencia cotidiana, conflictos armados, extorsiones, masacre, desplazamiento forzoso y hechos atroces impulsan estos procesos y, de esta manera, reconstruyen, repatrían y reinventan lo agrario y permanecen en sus territorios (ZuluagaSánchez y Arango-Vargas, 2013).

El conocimiento de los procesos en que se encuentran inmersas estas mujeres se logró mediante la participación de las investigadoras en las prácticas cotidianas de las campesinas, en los encuentros para la organización, las ferias de comercialización, los recorridos al campo y las visitas a los predios de las mujeres, entre otras acciones (Zuluaga-Sánchez y Arango-Vargas, 2013, pp. 163-167).

Los productos domesticados no son los únicos aprovechados para mejorar la producción y comercialización de los pequeños agricultores. La población aprovecha recursos forestales; entre ellos, están las palmas que permiten el equilibrio ecológico y tienen un uso amplio, sosteniendo la calidad de vida y cultura de las poblaciones donde estas existen (Paniagua, Busmann y Marcia, 2014, pp. 1-10).

En Paniagua et al. (2014, pp. 14-75), se describe la relevancia de 21 especies de palma y 276 tipos de uso de las mismas, reportadas por 89 personas, hombres y mujeres de distintas comunidades del sur del Perú. Su uso abarca la construcción de viviendas para paredes, pisos, techos, alimento y nutrición local, fabricación de utensilios, hamacas, bolsos, canastas, redes de pesca, esteras, herramientas de trabajo, alimento para animales, venta, combustible y aplicaciones medicinales.

Relacionado con lo anterior, Paz y Rodríguez (2004, pp. 59-78) encontraron que las iniciativas de innovación que impactan en lo local no siempre emanan de una planificación o de acciones individuales aisladas, sino por eventos y sucesos realizados por los actores que permiten impulsar el desarrollo. Esta experiencia se vivió con la producción lechera caprina, efectuada a base de la reconversión de la producción campesina materializándose en una importante cuenca lechera.

La diversidad de productos de origen agrícola para convertirlos en competitivos también abarca la producción de vino, bajo la consideración de que las ganancias por la exportación de un producto como este deben conservarse en los países de origen, como en el caso de Chile (Malo y Mari, 2003).

Como en diversos países de América Latina, en México, los pequeños productores también buscan las maneras de mejorar su producción y ser beneficiados en la comercialización.

El maíz y el frijol son los dos productos básicos esenciales para la dieta de millones de mexicanos, pero son de los productos con más bajo valor de la producción. Se llega a pagar 1.953 pesos por tonelada de maíz (poco más de 100 dólares) y 5507 (unos 250 dólares) por tonelada de frijol. Mientras que por el ajo, el precio medio regular por tonelada puede oscilar entre 7000 y 11000 mil pesos (de 350 a 550 dólares; Sagarpa, 2015).

La tendencia hacia la baja en la producción de estos productos básicos, ha generado un déficit y una presión mayor para satisfacer la demanda interna. Por ello, para el 2015 se realizarían importaciones de 10,9 millones de toneladas de maíz, equivalente al 45\% de lo que consumimos (El Financiero, 2014). En frijol, también se importa más de un millón de toneladas. 
Si bien los productores nacionales pueden satisfacer la demanda, no lo hacen por los precios bajos que reciben por sus productos, esto los ha llevado a dedicarse a otros cultivos más rentables, como la industria láctea, la producción vinícola, agrícola y ganadera.

Otra actividad con envergadura competitiva es la floricultura, vinculada a la economía global. Esta actividad se práctica en regiones de Guerrero y el Estado de México, al aprovechar la disponibilidad de los recursos naturales y las condiciones sociales para favorecer las unidades de producción familiar en el mercado nacional, mediante la generación de empleos y el mejoramiento en el nivel de ingresos (Orozco y Mendoza, 2003, pp. 30-37).

En México, las iniciativas se han enfocado a diversos rubros de la actividad agrícola. Entre ellos, se encuentra la agricultura orgánica en continuo crecimiento, tanto en salud y alimentación, conformada por pequeños productores con bajos niveles de ingreso, pero con perspectivas de desarrollo económico-social y ambiental (Boza, 2010, pp. 93-108).

Existen otras iniciativas enfocadas a mejorar la producción de maíz, considerando que no se satisface la demanda interna, no obstante, no se ha logrado un mejor precio del grano para los productores y mejorar el entorno rural (García, Rodríguez, Sáenz y Rebollar, 2006; Barkin, Fuente y Rosas, 2009; Osorio-García et. al., 2012). Por ello, hay casos en que los pequeños productores se enfocan en adoptar otros cultivos en busca de una mejora en su situación (Barrientos y Cardona, 2010).

\section{El Ejido Zaragoza}

Los pequeños productores del Ejido Zaragoza, objeto de estudio en esta investigación, han incursionado en el mercado nacional realizando algunos cambios en sus patrones de cultivo. Pertenecen al municipio de Sombrerete, ubicado en el Estado de Zacatecas, en el centro-norte de México.

Según el Censo de Población y Vivienda 2010 del Instituto Nacional de Estadística, Geografía e Informática (INEGI), en esta localidad también conocida como Francisco R. Murguía viven 1.123 habitantes, de los cuales 558 son hombres y 565 son mujeres. Del total de habitantes, la población económicamente activa es de 302 personas, 261 hombres y 41 mujeres. La población no activa económicamente es de 731, de los cuales 136 son hombres y 395 son mujeres. La población ocupada es de 294. De estos, 254 son hombres y 40 mujeres. La población sin derecho a servicios de salud es de 240 y con acceso a servicios de salud de 883 . Hay 237 hogares con jefatura masculina y 36 con jefatura femenina.

Es necesario indicar que los datos presentados sobre la población económicamente activa y ocupada, se refieren a aquellos que establecen una relación obrero patronal y se encuentran en los mercados de trabajo formales.

En la realidad, la población catalogada como no activa económicamente, tanto hombres como mujeres, se encuentran ocupados en actividades productivas no asalariadas, como la producción de básicos (maíz y frijol destinándole entre 5 y 10 hectáreas de tierra con rendimiento de 0,3 y 0,4 toneladas respectivamente) y actividades pecuarias, dirigidas al mercado y al autoconsumo.

Este Ejido se fundó en 1972. Fue el 14 de agosto de ese año cuando se le dotó de 49000 hectáreas de tierra, lo cual se concretó previo decreto presidencial con fecha del 19 de julio de ese mismo año para beneficio de 900 campesinos. Siendo ejido, entró al Programa de Certificación de Derechos Agrarios (Procede) el 14 de agosto de 1996 (RAN, 2015), dando fin al reparto agrario y dejando en la indefensión a sus descendientes, un fenómeno generalizado en México.

En promedio, cada ejidatario posee alrededor de 20 hectáreas de tierra cultivable, que trabaja desde la preparación para la siembra hasta la cosecha en condiciones particulares por su dependencia al temporal.

Estos pequeños productores ejidatarios son considerados campesinos porque sus tierras dependen del temporal, emplean trabajo familiar para los diversos procesos productivos que no están reconocidos en la contabilidad nacional por las instituciones correspondientes, venden al mercado a precios negociados bajo el modelo de oferta y demanda y recurren a una actividad de ayuda mutua ${ }^{1}$ cuando el trabajo familiar es insuficiente.

\section{La pertinencia de la producción de semilla de calabaza como estudio de caso}

Los pequeños productores de Sombrerete forman parte de uno de los distritos de desarrollo con mayor producción de frijol a nivel nacional.

\footnotetext{
1 En el sur de México, esta "ayuda mutua" es conocida como tequio; se trata de una actividad de los miembros de las sociedades indígenas que en cada parcela de cada ejidatario trabajan sin retribución económica con la finalidad de lograr la preparación de la tierra, la siembra, la cosecha y el acarreo de la producción primaria, entre otras actividades culturales según el proceso productivo de que se trate.
} 
Este producto ha reportado un descenso en la superficie sembrada. En el 2006, se sembraron más de 100 mil hectáreas pero en el 2014 se destinaron poco más de 92 mil hectáreas; pese a este descenso la productividad mejoró, porque en el 2014 no se reportaron pérdidas como sí ocurrió en el 2006 con más de 3 mil hectáreas.

La producción en toneladas mejoró en el 2014 al ubicarse en 92921 toneladas, lo que implica un rendimiento de 1,01 toneladas por hectárea. En el 2006, se obtuvieron 88193 toneladas con un rendimiento de 0,9 toneladas por hectárea. No obstante, el precio medio regular por tonelada apenas creció $32,18 \%$ al pasar de 5 104,16 pesos (unos 480 dólares) a 6746,31 pesos (unos 522 dólares) del 2006 al 2014 (tabla 1; Sagarpa, 2015).

En tanto, en la producción de semilla de calabaza, según datos disponibles en las localidades estudiadas, en el 2006 se cultivaron 795 hectáreas con un rendimiento de 0,55 toneladas por hectárea a un precio de 20000 pesos la tonelada (unos 1818 dólares; Encuesta propia, 2009). A partir del 2008, se comienzan a registrar datos de la producción de semillas de calabaza con una superficie sembrada de 3540 hectáreas con el $100 \%$ de superficie cosechada, con una producción de 1401 toneladas y 0,4 toneladas de rendimiento por hectárea con un precio promedio regular por tonelada de 12000 pesos (alrededor de 1090 dólares). Para el 2014, se sembraron 4200 hectáreas con un $100 \%$ de superficie cosechada, 2022 toneladas producidas con un rendimiento de 0,48 toneladas por hectárea y un precio medio regular de 41885,26 pesos por tonelada (unos 2478 dólares; Sagarpa, 2015), según la tabla 2.

Tabla 1.

Evolución de la producción y valor del frijol en Sombrerete, Zacatecas-México (2006-2014)

\begin{tabular}{ccccccc}
\hline Año & $\begin{array}{c}\text { Superficie Sem- } \\
\text { brada (Ha) }\end{array}$ & $\begin{array}{c}\text { Superficie Cose- } \\
\text { chada (Ha) }\end{array}$ & $\begin{array}{c}\text { Producción } \\
\text { (Toneladas) }\end{array}$ & $\begin{array}{c}\text { Rendimiento } \\
\text { (Ton/Ha) }\end{array}$ & PMR (\$/Ton) & $\begin{array}{c}\text { Valor de la Producción } \\
\text { Mieles de Pesos }\end{array}$ \\
\hline 2006 & 101572,00 & 98057,00 & 88193,00 & 0,9 & 5104,16 & 450151,00 \\
2007 & 63085,00 & 61910,00 & 43618,00 & 0,7 & 4016,9 & 175209,2 \\
2008 & 50346,00 & 45665,00 & 28557,00 & 0,62 & 10122,85 & 289078,3 \\
2009 & 65382,00 & 62582,00 & 62414,00 & 1,0 & 11759,23 & 733940,3 \\
2010 & 98034,00 & 97334,00 & 80105,00 & 0,82 & 6143,37 & 492115,00 \\
2011 & 90311,00 & 71211,00 & 31209,00 & 0,44 & 11780,58 & 367660,00 \\
2012 & 108683,00 & 108683,00 & 87352,37 & 0,8 & 9516,56 & 831293,66 \\
2013 & 125811,00 & 125811,00 & 118216,00 & 0,94 & 7578,8 & 895935,19 \\
2014 & 92004,00 & 92004,00 & 92921,00 & 1,01 & 6746,31 & 626874,16 \\
\hline
\end{tabular}

Nota: Elaboración propia con datos del siap de Sagarpa. Disponible en http://www.siap.gob.mx/cierre-de-la-produccion-agricola-por-estado/ consultado el 22/09/2015.

Tabla 2

Evolución de la producción y valor de la semilla de calabaza (chihua) en Sombrerete, Zacatecas-México (2006-2014)

\begin{tabular}{ccccccc}
\hline Año & $\begin{array}{c}\text { Superficie } \\
\text { Sembrada (Ha) }\end{array}$ & $\begin{array}{c}\text { Superficie } \\
\text { Cosechada }(\mathrm{Ha})\end{array}$ & $\begin{array}{c}\text { Producción } \\
\text { (Toneladas) }\end{array}$ & $\begin{array}{c}\text { Rendimiento } \\
\text { (Ton/Ha) }\end{array}$ & PMR (\$/Ton) & $\begin{array}{c}\text { Valor de la Produc- } \\
\text { ción Mieles de Pesos }\end{array}$ \\
\hline 2006 & NA & NA & NA & NA & NA & NA \\
2007 & NA & NA & NA & NA & NA & NA \\
2008 & 3540,00 & 3540,00 & 1401,00 & 0,4 & 12000,00 & 16812,00 \\
2009 & 2175,00 & 2125,00 & 932,00 & 0,44 & 30000,00 & 27960,00 \\
2010 & 4700,00 & 4700,00 & 2420,00 & 0,52 & 33000,00 & 79860,00 \\
2011 & 5266,00 & 4966,00 & 993,00 & 0,2 & 35000,00 & 34755,00 \\
2012 & 4869,00 & 4869,00 & 2906,79 & 0,6 & 35655,81 & 103643,94 \\
2013 & 3400,00 & 3400,00 & 1213,00 & 0,36 & 39204,45 & 47555,00 \\
2014 & 4200,00 & 4200,00 & 2022,00 & 0,48 & 41885,26 & 84692,00 \\
\hline
\end{tabular}

Nota: Elaboración propia con datos del siap de Sagarpa. Disponible en http://www.siap.gob.mx/cierre-de-la-produccion-agricola-por-estado/ consultado el 22/09/2015. 
De los datos se infiere que destinar un mayor número de superficie de tierras a los cultivos no necesariamente representa mayor rendimiento. De igual forma, el producir mayores volúmenes de granos no necesariamente se traducen en mejores precios y ganancias.

El frijol ya no es un cultivo rentable para los pequeños productores pero sí es rentable dedicarse al cultivo de calabaza y comercializar las semillas. Pese a destinar un número inferior de hectáreas sembradas, la superficie cosechada tiene una mayor certidumbre pese al temporal y los precios son más de $300 \%$ superior al frijol para el 2006 y $600 \%$ superior, en el 2014.

No obstante, el cultivo de granos básicos, en este caso el frijol, al que se suma el maíz y el chile, no han sido suspendidos ni la tierra ha sido reconvertida completamente, lo que se realiza, es un proceso de rotación de cultivos; es decir, el cultivo de calabazas se combina con la siembra de los granos básicos y otros productos agropecuarios, esenciales para la dieta del mexicano.

Como se dijo anteriormente, para el 2006, no existían datos sobre la producción de semillas de calabaza, estas se registran hasta el 2008 de manera oficial por la presión ejercida por parte de los productores del ejido objeto de estudio.

El conocimiento sobre la rentabilidad de la semilla de calabaza se consiguió con la realización de un diagnóstico en el 2007 sobre este producto, comparado con el frijol, fundamentalmente, por la vocación productiva de las regiones.

El estudio ${ }^{2}$ arrojó que los pequeños productores efectuaban la preparación de la tierra, la siembra y la cosecha con serias dificultades y los apoyos del gobierno se limitaban al acceso de los recursos del Programa de Apoyos Directos al Campo (procampo) que asciende a 95,5 dólares por hectárea.

Pese a que los recursos otorgados por este programa se deben destinar para los procesos productivos de los granos básicos, estos suelen ser empleados para el autoconsumo y la adquisición de útiles escolares para los hijos de los campesinos o cualquier otro fin, menos para lo que se encuentran etiquetados.

Otro problema que enfrentaban los productores era la crisis climática, lo cual los orilló a ampliar su

Fue realizado por un descendiente campesino deportado de Estados Unidos por su condición de migrante ilegal, egresado de la Licenciatura en Economía por la Universidad Autónoma de Zacatecas (UAZ) en México, que buscaba un empleo bien remunerado ante la falta de oportunidades en su localidad de origen. producción a cultivos más rentables y resistentes a la escasez de agua. El que más sobresalió fue la producción de semilla de calabaza. Sin embargo debían considerar colocar su producto en el mercado.

Por ello, se realizó un estudio en el que se observó que el cultivo de la calabaza se desarrollaba de manera incipiente por los campesinos del municipio, al cultivar como mínimo cinco hectáreas de este producto. A partir de este fenómeno, la curiosidad del porqué de esta situación de la siembra de semilla de calabaza atraía a los campesinos se intensificó e hizo dirigir una búsqueda de alternativas para encontrar los apoyos necesarios para el beneficio del cultivo y de los campesinos ya familiarizados con la siembra y cosecha de calabaza.

En el proceso, se detectó que existían pocos registros de datos del cultivo de calabaza en instancias como Sagarpa y en ese entonces la Secretaría de Desarrollo Agropecuario (Sedagro), ahora Secretaría del Campo (Secampo). Por ello, los apoyos hacia este cultivo eran totalmente nulos, pues estadísticamente se desconocía de su incorporación a la agricultura del Estado.

Con estas consideraciones presentes, se diseñó una encuesta para saber la superficie real cultivada y detectar desde hace cuánto tiempo se ha desarrollado la práctica agrícola de este producto, con el objetivo de justificar las desventajas existentes y contrarrestarlas con un planteamiento claro.

La encuesta de diez preguntas abiertas se aplicó en las comunidades de Ex Hacienda Zaragoza, Plan de Guadalupe, Charco Blanco, Alfredo V. Bonfil y José María Morelos a pequeños productores que previamente fueron identificados como productores de semillas de calabaza, lo cual se obtuvo mediante una interrogación a los Comisariados Ejidales de dichas comunidades y que son parte de la región frijolera del municipio de Sombrerete (tablas 3-8).

El trabajo de campo arrojó la cantidad real de superficie sembrada del grupo inicial de pequeños productores que habían decidido organizarse y en el futuro serían socios y el resto de los pequeños productores. También proporcionó el dato del primer ciclo de siembra de calabaza en superficie sembrada, rendimiento promedio de la superficie cultivada, rendimiento por hectárea, valor de la producción, precio promedio por kilo y tonelada. A partir de aquí, se dio el seguimiento al campesino que siembra calabaza considerando los precios favorables y rentabilidad en la comercialización respecto al frijol, por ser de los principales granos cultivados en Sombrerete. 
Tabla 3

Producción de semilla de calabaza de los socios de Semilla Casa Grande: superficie sembrada, cosechada, rendimiento, precio medio y precios pagados

\begin{tabular}{cccccc}
\hline $\begin{array}{c}\text { Semillas Casa } \\
\text { Grande }\end{array}$ & $\begin{array}{c}\text { Superficie Sembra- } \\
\text { da/Ha }\end{array}$ & Cosecha en Ton/Ha & $\begin{array}{c}\text { Porcentaje de Ren- } \\
\text { dimiento Kg/Ha }\end{array}$ & Precio/Media & Precios pagados \\
\hline 2000 & 6 & 4 & 0,67 & 20 & $20-22$ \\
2001 & 20 & 15 & 0,75 & 21 & $22-25$ \\
2002 & 35 & 20 & 0,57 & 20 & $18-20$ \\
2003 & 40 & 30 & 0,75 & 25 & $18-22$ \\
2004 & 50 & 29 & 0,58 & 24 & $20-27$ \\
2005 & 65 & 37 & 0,57 & 20 & $22-27$ \\
2006 & 80 & 44 & 0,55 & 23 & $17-21$ \\
2007 & 90 & 51 & 0,57 & 28 & $19-30$ \\
2008 & 95 & 0,57 & 42 & $28-37$ \\
2009 & 150 & $67+5$ & 0,45 & 38 & $42-44$ \\
2010 & 300 & 135 & 0,45 & 29 & $38-42$ \\
2011 & 400 & 80 & 0,20 & & $29-35$ \\
\hline
\end{tabular}

Nota. Elaboración propia de encuesta aplicada en el 2009.

Tabla 4

Producción de semillas de calabaza de la comunidad Exhacienda Zaragoza: superficie sembrada, cosechada, rendimiento, precio medio y precios pagados

\begin{tabular}{cccccc}
\hline \multicolumn{5}{c}{ Productores encuestados: 75} \\
\hline $\begin{array}{c}\text { Comunidad Exha- } \\
\text { cienda Zaragoza }\end{array}$ & $\begin{array}{c}\text { Superficie Sembra- } \\
\text { da/Ha }\end{array}$ & Cosecha en Ton/Ha & $\begin{array}{c}\text { Porcentaje de Ren- } \\
\text { dimiento Kg/Ha }\end{array}$ & Precio/Media & Precios pagados \\
\hline 1998 & 5 & 3,5 & 0,70 & 20 & $20-22$ \\
1999 & 30 & 16,5 & 0,55 & 21 & $22-25$ \\
2000 & 50 & 28 & 0,56 & 21 & $18-22$ \\
2001 & 65 & 32 & 0,49 & 25 & $20-27$ \\
2002 & 80 & 37 & 0,46 & 24 & $22-27$ \\
2003 & 120 & 55 & 0,46 & 20 & $22-27$ \\
2004 & 170 & 80 & 0,47 & 23 & $17-21$ \\
2005 & 150 & 65 & 0,43 & 28 & $19-30$ \\
2006 & 160 & 68 & 0,43 & 30 & $28-37$ \\
2007 & 205 & 97 & 0,47 & 35 & $29-32$ \\
2008 & 270 & 125 & 0,46 & 39 & $33-35$ \\
2009 & 350 & 165 & 0,47 & & $39-44$ \\
\hline
\end{tabular}

Nota. Elaboración propia de encuesta aplicada en el 2009. 
Tabla 5

Producción de semillas de calabaza de la comunidad Plan de Guadalupe: superficie sembrada, cosechada, rendimiento, precio medio y precios pagados

\begin{tabular}{cccccc}
\hline & \multicolumn{5}{c}{ Productores encuestados: 20 } \\
\hline Plan de Guadalupe & $\begin{array}{c}\text { Superficie } \\
\text { Sembrada/Ha }\end{array}$ & $\begin{array}{c}\text { Cosecha en } \\
\text { Ton/Ha }\end{array}$ & $\begin{array}{c}\text { Porcentaje de } \\
\text { Rendimiento Kg/Ha }\end{array}$ & Precio/Media & Precios pagados \\
\hline 1999 & 3 & 2 & 0,67 & 20 & $20-22$ \\
2000 & 13 & 7,8 & 0,60 & 21 & $22-25$ \\
2001 & 35 & 17 & 0,49 & 21,5 & $18-20$ \\
2002 & 50 & 32 & 0,64 & 25 & $18-22$ \\
2003 & 65 & 37 & 0,57 & 24 & $20-27$ \\
2004 & 90 & 48 & 0,53 & 20 & $22-27$ \\
2005 & 120 & 55 & 0,46 & 23 & $17-21$ \\
2006 & 150 & 65 & 0,43 & 28 & $19-30$ \\
2007 & 160 & 68 & 0,43 & 30 & $28-37$ \\
2008 & 200 & 98 & 0,49 & 41 & $29-32$ \\
2009 & 280 & 135 & 0,48 & & $40-44$ \\
\hline
\end{tabular}

Nota. Elaboración propia de encuesta aplicada en el 2009.

Tabla 6

Producción de semillas de calabaza de la comunidad de Charco Blanco: superficie sembrada, cosechada, rendimiento, precio medio y precios pagados

\begin{tabular}{|c|c|c|c|c|c|}
\hline \multicolumn{6}{|c|}{ Productores encuestados: 100} \\
\hline $\begin{array}{l}\text { Comunidad Exha- } \\
\text { cienda Zaragoza }\end{array}$ & $\begin{array}{c}\text { Superficie } \\
\text { Sembrada/Ha }\end{array}$ & $\begin{array}{c}\text { Cosecha en } \\
\text { Ton/Ha }\end{array}$ & $\begin{array}{l}\text { Porcentaje de Ren- } \\
\text { dimiento } \mathrm{Kg} / \mathrm{Ha}\end{array}$ & Precio/Media & Precios pagados \\
\hline 1996 & 5 & 3 & 0,60 & 20 & $20-22$ \\
\hline 1997 & 20 & 9,5 & 0,48 & 21 & $22-25$ \\
\hline 1998 & 45 & 22,5 & 0,50 & 21 & $18-20$ \\
\hline 1999 & 50 & 32 & 0,64 & 21,5 & $18-22$ \\
\hline 2000 & 80 & 39 & 0,49 & 25 & $20-27$ \\
\hline 2001 & 150 & 65 & 0,43 & 24 & $22-27$ \\
\hline 2002 & 180 & 80 & 0,44 & 20 & $17-21$ \\
\hline 2003 & 240 & 130 & 0,54 & 23 & $19-30$ \\
\hline 2004 & 265 & 137 & 0,52 & 28 & $28-37$ \\
\hline 2005 & 200 & 98 & 0,49 & 21 & $29-32$ \\
\hline 2006 & 280 & 135 & 0,48 & 23 & $40-44$ \\
\hline 2007 & 300 & 145 & 0,48 & 30 & $29-41$ \\
\hline 2008 & 450 & 210 & 0,47 & 31 & $30-38$ \\
\hline 2009 & 650 & 305 & 0,47 & 41 & $38-44$ \\
\hline
\end{tabular}

Nota. Elaboración propia de encuesta aplicada en el 2009. 
Tabla 7

Producción de semillas de calabaza de la comunidad Alfredo V. Bonfil: superficie sembrada, cosechada, rendimiento, precio medio y precios pagados

\begin{tabular}{|c|c|c|c|c|c|}
\hline \multicolumn{6}{|c|}{ Productores encuestados: 16} \\
\hline Alfredo V. Bonfil & $\begin{array}{c}\text { Superficie } \\
\text { Sembrada/Ha }\end{array}$ & $\begin{array}{c}\text { Cosecha en } \\
\text { Ton/Ha }\end{array}$ & $\begin{array}{c}\text { Porcentaje de } \\
\text { Rendimiento Kg/Ha }\end{array}$ & Precio/Media & Precios pagados \\
\hline 2000 & 1 & 0,4 & 0,40 & 22 & 22 \\
\hline 2001 & & & & & \\
\hline 2002 & 4 & 1,9 & 0,48 & 18 & 18 \\
\hline 2003 & 4 & 1,9 & 0,48 & 20 & $18-22$ \\
\hline 2004 & 26 & 12,4 & 0,48 & 20,75 & $18-25$ \\
\hline 2005 & 60 & 25,2 & 0,42 & 17.375 & $14-20$ \\
\hline 2006 & 103,5 & 38,7 & 0,37 & 17,16 & $15-25$ \\
\hline 2007 & 99 & 34,4 & 0,35 & 23,58 & $18-30$ \\
\hline 2008 & 101,5 & 37,4 & 0,37 & 30,38 & $18-40$ \\
\hline 2009 & 118,5 & & & & \\
\hline
\end{tabular}

Nota. Elaboración propia de encuesta aplicada en el 2009.

Tabla 8

Producción de semillas de calabaza de la comunidad José Maria Morelos: superficie sembrada, cosechada, rendimiento, precio medio y precios pagados

\begin{tabular}{cccccc}
\hline \multicolumn{5}{c}{ Productores encuestados 10 } \\
\hline José Maria Morelos & $\begin{array}{c}\text { Superficie } \\
\text { Sembrada/Ha }\end{array}$ & $\begin{array}{c}\text { Cosecha en } \\
\text { Ton/Ha }\end{array}$ & $\begin{array}{c}\text { Porcentaje de } \\
\text { Rendimiento Kg/Ha }\end{array}$ & Precio/Media & Precios pagados \\
\hline 2000 & 9 & 7 & 0,78 & 16 & $15-17$ \\
2001 & 5 & & & 12 & 12 \\
2002 & 3,5 & 2,3 & 0,46 & 15 & 15,3 \\
2003 & 11 & 1,8 & 0,51 & 19,4 & $17-20$ \\
2004 & 28,5 & 5,1 & 0,46 & 21,8 & $17-22$ \\
2005 & 21,5 & 12 & 0,37 & 23,6 & $18-28$ \\
2006 & 46,5 & 7,9 & 0,42 & 26,8 & $18-30$ \\
2007 & 80 & 19,3 & 0,33 & & $20-35$ \\
\hline
\end{tabular}

Nota. Elaboración propia de encuesta aplicada en el 2009. 
Con los datos recabados, se explica el vuelco de los campesinos a la agricultura de la región, pues la mayoría tiene experiencia de diez años, es decir, conoce el manejo del cultivo, los costos más bajos, el precio rentable y el mercado accesible a nivel nacional.

La investigación de campo mostró también la tendencia a duplicar la superficie sembrada y la evolución de los precios. Es en estos últimos en los que se observa un descenso debido al factor clima, el cual marca y determina la calidad de la semilla de calabaza y los aspectos del financiamiento agrícola.

El mercado de la semilla de calabaza es diverso. Sus múltiples usos obligan a mantener una atención constante en la demanda entre la cual se encuentran la semilla tostada con sal como botana, la elaboración del pipián, la preparación de mole, la elaboración de aceites gastronómicos y el suplemento médico, entre otras.

La investigación de campo, fortaleció el factor de la comercialización porque con las respuestas de los sujetos campesinos encuestados, se conoció que el origen de los compradores es de Coahuila, Chihuahua, Durango, San Luis Potosí, Guanajuato, Guadalajara y el Estado de México.

\section{La formación de una sociedad mercantil}

Con el diagnóstico disponible se formó una sociedad de 32 productores denominada Semillas Casa Grande Zaragoza, sc de RL de Cv. En una asamblea acordaron sus derechos y obligaciones, direccionaron sus metas como organización.

Teniendo en cuenta que son los iniciadores de un proyecto novedoso en el Estado de Zacatecas, se previó actuar con los pies sobre la tierra para formular la propuesta de un proyecto justificado con los datos del diagnóstico, para obtener apoyos o en su caso financiamiento del Gobierno Federal.

Bajo consenso se determinó que la prioridad era consolidar la tecnificación para la siembra y la cosecha, un centro de almacenaje para concentrar la producción y atraer a los compradores a un solo lugar, evitando la compra-venta casa por casa y ser víctimas de bajos precios.

También se consideró la elaboración de un plan de negocios para combatir a compradores intermediarios y contactar incluso el consumidor final, esto es, las empresas nacionales dedicadas a la transformación de la semilla de calabaza, para lograr contratos firmes de comercialización cada ciclo y de esta manera asegurar un mercado sin especular el precio.

Los campesinos estuvieron atentos al desarrollo de la elaboración y diseño del proyecto de inversión, para manejarse en dos etapas. En la primera, con la terminación del proyecto con gestión de recursos en el Gobierno Federal, y en la segunda, mediante el apuntalamiento en la búsqueda del mercado nacional para asegurar la comercialización de cada ciclo productivo.

La búsqueda de compradores fue la parte más compleja por las condiciones económicas precarias de la organización de productores, porque las entidades a visitar son de una actividad comercial intensiva, por lo que las expectativas para conocer el mercado no fueron las más satisfactorias.

Pese a la complejidad, se conoció el mercado de septiembre a noviembre del 2009, logrando solo la respuesta de una comunicación posterior en tiempos comerciales, que se emprendieron los primeros días del 2010, cuando se estableció comunicación con una empresa nacional del Estado de Guanajuato, dedicada a la maquila de semilla tostada para empresas como Barcel y Sabritas.

Con estas empresas, se firmó un contrato por diversos ciclos comerciales en los años venideros. El plan de negocios logró ser eficaz, con lo cual se respaldó al campesino en la comercialización y como miembro de una organización sólida de pequeños productores que comenzó a sobresalir en la región.

Los primeros recursos obtenidos de la relación con empresas privadas se entregaron en un evento público en marzo del 2010, resaltando la participación de un grupo de investigadores de la Unidad Académica de Economía de la Universidad Autónoma de Zacatecas que acompañaron a los productores en el diseño, implementación y seguimiento de los recursos públicos de la cadena productiva semilla de calabaza.

Su apoyo fue indispensable para concluir satisfactoriamente la parte financiera y teórica, dejando en manos de los pequeños productores la parte empírica. Mientras se fortalecían las relaciones con la iniciativa privada, los pequeños productores entregaban simultáneamente en el mismo mes y año un proyecto de inversión en la Delegación Federal de Sagarpa para maquinaria y equipo, destacando siempre las energías y esperanzas de los campesinos para ser competitivos en la producción, la comercialización, los ingresos e involucrando a los excluidos de mediados de la década de los noventa del siglo pasado, catalogados como 
avecindados sin derechos a un pedazo de tierra, sujetos a la herencia de los titulares.

\section{Conclusiones}

Esta experiencia de competitividad de los pequeños productores es compartida con la idea de transmitir el camino recorrido para lograr vincularse con el mercado nacional, con un producto de alto potencial productivo y comercial conocido inicialmente solo por los mismos productores y aprovechado por intermediarios informales.

Se trata de una experiencia en la que se involucran los pequeños productores, una institución pública de nivel superior y sus egresados en el eje de extensión con el sector productivo agrícola, para volver competitivos a los pequeños agricultores y como efecto secundario, mejorar las condiciones de vida de la población.

El cambio se debe a la misma iniciativa de los campesinos, en su idea de mejorar los precios de sus productos involucrando a su descendencia que no tiene la posibilidad de acceder a tierras por la vía de la dotación del Estado.

Los datos proporcionados por los pequeños productores, indican que el principal cultivo de su región es el frijol, cultivo con el que han ocupado los primeros lugares a nivel nacional por su volumen de producción, catalogándolos como región friolera por excelencia.

También han producido un producto de mayor valor comercial pero hacía falta fortalecer la parte de su comercialización, eliminando el comercio ilegal o coyotaje como se le conoce en México, el cual oferta precios inferiores a los realmente establecidos en el mercado de oferta y demanda. En estos casos, la vinculación de la universidad con el resto de la sociedad cobra relevancia para volver competitivos a los pequeños productores, pero sin que estos abandonen el autoconsumo.

Es decir, dentro de las reglas de funcionamiento de la organización de productores de semillas de calabaza, se tiene prohibido cultivar más de 10 hectáreas de este producto; esto significa que tienen derecho a cultivar entre 5 y 10 hectáreas y el resto de sus tierras deben ser destinadas al cultivo de granos básicos, esencialmente, maíz y frijol para garantizar la alimentación. Aunque se debe reconocer que, pese a ser cultivos de temporal, el más resistente a la sequía y a las heladas es la semilla de calabaza.
Esta manera de producir ha permitido a los campesinos no verse impactados negativamente con los precios internacionales, guardando celosamente la bondad de la calidad de sus tierras al realizar la rotación de cultivos para equilibrar los nutrientes y beneficiar a cada producto, lo cual les ha hecho posible enfrentarse al mismo producto proveniente de otros países como la India. La calidad de su producto no ha sido equiparada hasta este momento, la semilla mexicana sigue siendo la mejor en sabor y textura.

Como sociedad productora, ha mantenido un camino complejo, sin embargo, la persistencia de sus integrantes también les ha permitido avanzar más que otros productores de entidades de México como Coahuila, Yucatán y Guanajuato. Los de Zacatecas producen semillas para el mercado nacional e internacional pero siempre garantizando la alimentación y subsistencia familiar.

Resta decir que este caso de campesino sostenible y sustentable no inició el camino con una propuesta teórica, si no con evidencia empírica, un problema real que se transformó en teórico para reconocerse campesinos, lo cual les ha facilitado el acceso al financiamiento público, convirtiéndose reiteradamente en unos de los mejores proyectos productivos y de inversión del campesino hasta la fecha.

Esta iniciativa exitosa también ha representado un reto para la academia, que al abordar temas vinculados con procesos productivos, ha trascendido más allá de relacionar variables, atendiendo un problema real, sentido por las comunidades rurales ejidales-campesinas.

\section{Referencias}

Barkin, D., Fuente, M. E. y Rosas, M. (2009). Tradición e innovación. Aportaciones campesinas en la orientación de la innovación tecnológica para forjar sustentabilidad. Revista Trayectorias, 11(29), 39-54.

Barrientos, J. C. y Cardona, J. O. (2010). Los pequeños productores están limitados para adoptar nuevos cultivos. El caso de las hierbas aromáticas en la región de Sumapaz, Cundinamarca. Revista Agronomía Colombiana, 28(1), 99-106.

Bartra, A. (2006). El capital en su laberinto. México: Editorial itaca.

Boza, S. (2010). Desafío del desarrollo: la agricultura orgánica como parte de una estrategia de mitigación de la pobreza rural en México. Nóesis. Revista de Ciencias Sociales y Humanidades, 19 (37), pp. 92-111. 
Buendía, E. (2013). El papel de la ventaja competitiva en el desarrollo económico de los países. Revista Análisis Económico, xxvini(69). México. 55-78.

Cruz, M. (2011). Las bondades del trabajo femenino. Tres segmentos de mujeres rurales en Zacatecas (1980-2010). Tesis de Maestría. UAZ, México.

El Financiero. (2014). México importará 45\% del maíz que consumirá en 2014-2015. Recuperado de http:// www.elfinanciero.com. $\mathrm{mx} / \mathrm{mercados} /$ commodities/mexico-importara-45-del-maiz-que-consumira-en-2014-2015.html

Encuesta. (2009). Productores de calabaza del municipio de Sombrerete, Zacatecas-México.

García, J. A., Rodríguez, G., Sáenz, A. y Rebollar, S. (2006). Políticas para mejorar la competitividad de la producción de maíz y frijol en México. Revista Fitotecnia Mexicana, 29(2), 115-121.

Inegi. (2010). Censo de Población y Vivienda 2010. Recuperado de http://www.inegi.org.mx/est/contenidos/ proyectos/ccpv/cpv2010/Default.aspx

Malo, M. C. y Mori, T. (2003). Impactos del comercio justo del vino. Tres casos de empresas colectivas de productores de Chile. Revista de Economía Pública, Social y Cooperativa, 46, 265-289.

Ministerio de Agricultura del Perú. (s. f.). Ministerio de Agricultura continúa trabajando para mejorar la competitividad de los pequeños y medianos productores del país (pp.17-20). Agroideas.

Orozco, M. E. y Mendoza, M. (2003). Competitividad local de la agricultura ornamental en México. Revista Ciencia ergo Sum, 10(1), México, 29-42.
Osorio-García, N., López-Sánchez, H., Gil-Muñoz, A., Ramírez-Valverde, B., Gutiérrez-Rangel, N., Crespo-Pichardo, G. y Montero-Pineda, A. (2012). Utilización, oferta y demanda de tecnología para producción de maíz en el valle de Puebla, México. Revista Agricultura, Sociedad y Desarrollo, 9(1), 55-69.

Paniagua, N., Busmann, R. W. y Macia, M. J. (2014). El bosque si tiene valor: el uso de las palmeras en las comunidades campesinas e indígenas de la región de Inambari, Madre de Dios, Perú. Ethnobotany research \& Applications. A Journal of Plants, People and Applied Research.

Paz, R. y Rodríguez, R. (2004). Tramas productivas e iniciativas de desarrollo local: la lechería caprina con pequeños productores del área de riego de Santiago del Estero. Revista Territorios, 12, 59-78.

Rubio, B. (2002). Explotados y excluidos. Los campesinos latinoamericanos. México: Editorial Plaza y Valdez.

Secretaría de Agricultura, Ganadería, Desarrollo rural, Pesca y Alimentación [Sagarpa] y Servicio de Información Agroalimentaria y Pesquera [sIAP]. (2015). Cierre de la producción agrícola por estado. Recuperado de http:// www.siap.gob.mx/cierre-de-la-produccion-agricola-por-estado/ consultado el 22/09/2015

Sobrino, L. J. (2002). Competitividad y ventajas competitivas: revisión teórica y ejercicio de aplicación a 30 ciudades de México. Revista Estudios Demográficos y Urbanos. 50, 311-361.

Zuluaga-Sánchez, G. P. y Arango-Vargas, C. (2013). Mujeres campesinas: resistencia, organización y agroecología en medio del conflicto armado. Revista Cuadernos de Desarrollo Rural, 10(72), 159-180. 